\title{
Benefit/Risk Profile of Single-Inhaler Triple Therapy in COPD
}

This article was published in the following Dove Press journal:

International Journal of Chronic Obstructive Pulmonary Disease

\author{
Jean Bourbeau' \\ Mona Bafadhel $\mathbb{D}^{2}$ \\ Neil C Barnes $\mathbb{D}^{3,4}$ \\ Chris Compton ${ }^{3}$ \\ Valentina Di Boscio ${ }^{3}$ \\ David A Lipson (D) ${ }^{5,6}$ \\ Paul W Jones $\mathbb{D}^{3,7}$ \\ Neil Martin ${ }^{3,8}$ \\ Gudrun Weiss ${ }^{3}$ \\ David MG Halpin (1) 9
}

\begin{abstract}
'Respiratory Epidemiology and Clinical Research Unit, Department of Medicine, McGill University and Research Institute of the McGill University Health Centre, Montreal, QC, Canada; ${ }^{2}$ Nuffield Department of Medicine, University of Oxford, Oxford, Oxfordshire, UK;

${ }^{3}$ Respiratory Therapy Area, GlaxoSmithKline, Brentford, Middlesex, UK; ${ }^{4}$ William Harvey Institute, Bart's and the London School of Medicine and Dentistry, London, UK; ${ }^{5} \mathrm{Clinical}$ Sciences, GlaxoSmithKline, Collegeville, PA, USA; ${ }^{6}$ Pulmonary, Allergy and Critical Care Division, Department of Medicine, Perelman School of Medicine, University of Pennsylvania, Philadelphia, PA, USA; ${ }^{7}$ Institute of Infection and Immunity, St George's, University of London, London, UK; ${ }^{8}$ University of Leicester, Leicester,

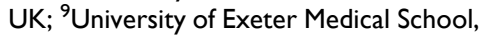
College of Medicine and Health, University of Exeter, Exeter, UK
\end{abstract}

Correspondence: Jean Bourbeau McGill University Health Centre (MUHC), I00I Decarie Boulevard, Montreal, QC, H4A 3JI, Canada

Tel + I 514 934-1934

$\mathrm{Fax}+1514934-8577$

Email jean.bourbeau@mcgill.ca

\begin{abstract}
Chronic obstructive pulmonary disease (COPD) is associated with major healthcare and socioeconomic burdens. International consortia recommend a personalized approach to treatment and management that aims to reduce both symptom burden and the risk of exacerbations. Recent clinical trials have investigated single-inhaler triple therapy (SITT) with a long-acting muscarinic antagonist (LAMA), long-acting $\beta_{2}$-agonist (LABA), and inhaled corticosteroid (ICS) for patients with symptomatic COPD. Here, we review evidence from randomized controlled trials showing the benefits of SITT and weigh these against the reported risk of pneumonia with ICS use. We highlight the challenges associated with crosstrial comparisons of benefit/risk, discuss blood eosinophils as a marker of ICS responsiveness, and summarize current treatment recommendations and the position of SITT in the management of COPD, including potential advantages in terms of improving patient adherence. Evidence from trials of SITT versus dual therapies in symptomatic patients with moderate to very severe airflow limitation and increased risk of exacerbations shows benefits in lung function and patient-reported outcomes. Moreover, the key benefits reported with SITT are significant reductions in exacerbations and hospitalizations, with data also suggesting reduced all-cause mortality. These benefits outweigh the ICS-class effect of higher incidence of study-reported pneumonia compared with LAMA/LABA. Important differences in trial design, baseline population characteristics, such as exacerbation history, and assessment of outcomes, have significant implications for interpreting data from cross-trial comparisons. Current understanding interprets the blood eosinophil count as a continuum that can help predict response to ICS and has utility alongside other clinical factors to aid treatment decision-making. We conclude that treatment decisions in COPD should be guided by an approach that considers benefit versus risk, with early optimization of treatment essential for maximizing long-term benefits and patient outcomes.
\end{abstract}

Keywords: all-cause mortality, exacerbations, hospitalizations, ICS, LABA, LAMA

\section{Introduction}

Chronic obstructive pulmonary disease (COPD), the third leading cause of death worldwide, ${ }^{1}$ is a major healthcare burden and a common cause of hospital admissions. The progressive nature of the disease is likely to impact on work productivity and, in many countries, this may contribute to higher rates of premature retirement and subsequent loss of income. ${ }^{2}$ The treatment and management of COPD also carries a significant economic burden, ${ }^{3,4}$ which is mainly attributed to exacerbations of COPD, particularly those leading to hospitalization. ${ }^{5-8}$ These have serious clinical implications, resulting in an expedited decline of lung function, decreased health-related quality of life, and increased risk of rehospitalization and mortality. ${ }^{9-11}$ Prevention of 
exacerbations and hospitalizations is a major goal of treatment strategies yet remains a significant unmet need. ${ }^{11}$

The Global Initiative for Chronic Obstructive Lung Disease (GOLD) 2020 Strategy report recommends a personalized approach for the treatment and management of patients with COPD. ${ }^{3}$ The aim is to reduce both symptom burden and the risk of future exacerbations. Smoking cessation remains the most important modifiable risk factor influencing disease progression in COPD. ${ }^{3}$ Despite treatment recommendations such as those in the GOLD report, observations from clinical practice suggest some divergence in prescribing. ${ }^{12-18}$ There remains much inertia in how physicians manage and treat COPD, with many primary care providers either choosing to deviate from guideline-indicated treatment or being unaware of these guidelines. ${ }^{19}$ It is unknown whether more clearly defined recommendations incorporating exacerbation risk and blood eosinophil count to guide therapy within recently developed frameworks will help to change this. One of the main challenges is to identify those patients whom optimizing therapy can help drive better disease outcomes.

Initial pharmacological therapy for COPD centers on the use of short- and long-acting bronchodilators. Escalation of treatment for patients with symptomatic COPD and at risk of exacerbations includes combined therapy of long-acting bronchodilator and/or inhaled corticosteroid (ICS) containing regimens. ${ }^{3}$ The emerging clinical trial data examining single-inhaler triple therapy (SITT) with a long-acting muscarinic antagonist (LAMA), long-acting $\beta_{2}$-agonist (LABA) and ICS for patients with symptomatic COPD and at risk of exacerbations ${ }^{20-26}$ has driven further debate around optimizing treatment for these patients. ${ }^{27-29}$

A recent systematic review and meta-analysis has highlighted the superior benefit/risk profile of triple therapy over dual or mono-bronchodilator therapy in patients with a history of exacerbations, noting that in such patients the reduction in exacerbations outweighs the risk of pneumonia. ${ }^{30}$ This article reviews evidence from randomized controlled trials (RCTs) that investigated the benefits of SITT for improving lung function and reducing symptoms, exacerbations, hospitalizations, and mortality in patients with COPD compared with those on dual combination therapy, and weighs these against the risk of pneumonia associated with ICS use. We highlight the benefits of SITT on all-cause mortality, explore the limitations of cross-trial comparisons and discuss the role of blood eosinophils as a marker of response to ICS.
Finally, we summarize current treatment recommendations and the position of SITT in the management of COPD.

\section{Evaluating the Benefits of SITT in COPD: Lessons from the Literature}

There is a growing body of evidence that treatment with SITT improves lung function, symptoms, and healthrelated quality of life and reduces moderate and severe exacerbations in patients with symptomatic COPD. Here, we present an overview of the clinical trials examining the efficacy and safety of SITT in patients with COPD.

\section{Trials with Lung Function as the Primary Endpoint}

The TRILOGY, KRONOS and FULFIL trials had primary endpoints of lung function, symptoms and/or health-related quality of life (Table 1). Baseline patient characteristics for these studies are provided in Table 2. TRILOGY compared beclometasone dipropionate (BDP)/formoterol fumarate (FM)/glycopyrronium bromide (GLY) with BDP/FM over 52 weeks in 1367 patients with symptomatic COPD (with a post-bronchodilator forced expiratory volume in 1 second $\left[\mathrm{FEV}_{1}\right]<50 \%$, and at least one exacerbation in the previous year). ${ }^{25}$ During the 2-week run-in period, patients received BDP/FM (Table 1). ${ }^{25}$ KRONOS was a 24-week trial comparing budesonide (BUD)/GLY/FM with FM/GLY, BUD/FM and open-label BUD/FM (delivered by dry powder inhaler [DPI]) in 1896 patients with symptomatic but non-exacerbating COPD (74\% of patients had no exacerbations in the preceding year). ${ }^{20}$ Patients received ipratropium bromide as maintenance medication during the run-in period and the use of ICS was permitted (Table 1). ${ }^{20}$ In the FULFIL trial, fluticasone furoate $(\mathrm{FF}) / \mathrm{umeclidinium}$ (UMEC)/vilanterol (VI) was compared with BUD/FM (via DPI) over 24 weeks in 1810 patients with symptomatic COPD (either with $\mathrm{FEV}_{1}<50 \%$ predicted, or with $\mathrm{FEV}_{1}$ $50-<80 \%$ predicted and at least two moderate or one severe exacerbation in the preceding year). ${ }^{21}$ Patients' COPD maintenance medication was unchanged during the run-in period (Table 1), to more closely resemble clinical practice. ${ }^{21}$ A subset of patients remained on study treatment for up to 52 weeks. $^{21}$

All three trials showed significant improvements in lung function with SITT versus dual therapy. In TRILOGY, SITT improved trough $\mathrm{FEV}_{1}$ by $63 \mathrm{~mL}$ at 52 weeks ( $81 \mathrm{~mL}$ at 26 weeks) compared with ICS/LABA, in KRONOS a 59-74 mL improvement was seen with SITT 


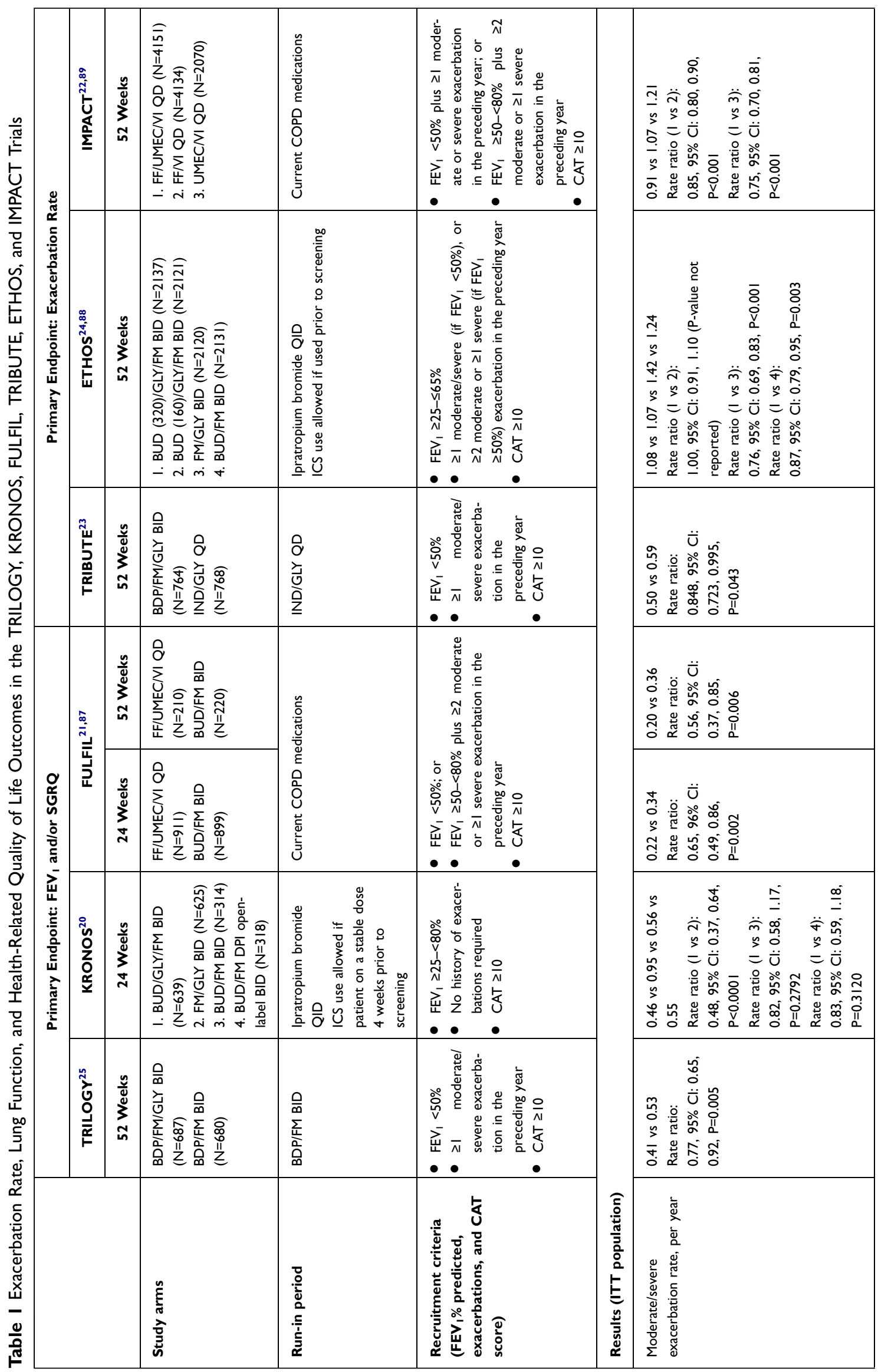




\begin{tabular}{|c|c|c|c|c|c|c|}
\hline$\stackrel{\Xi}{\Perp}$ & 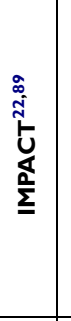 & 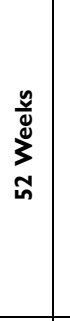 & 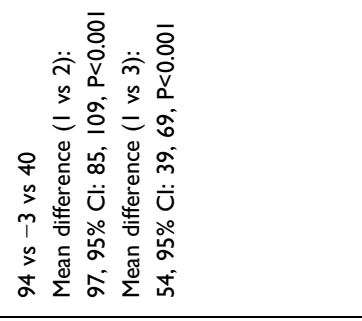 & 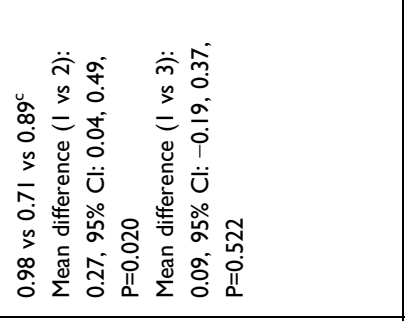 & 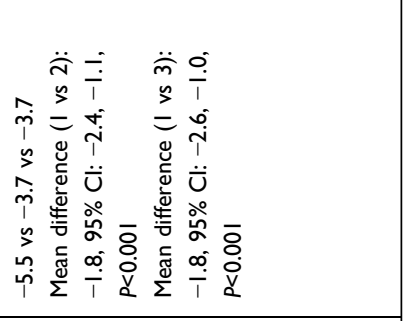 & 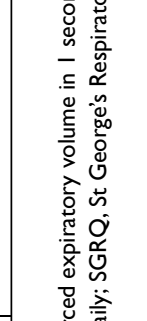 \\
\hline & 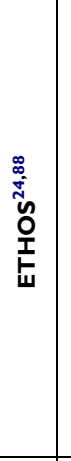 & 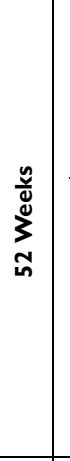 & 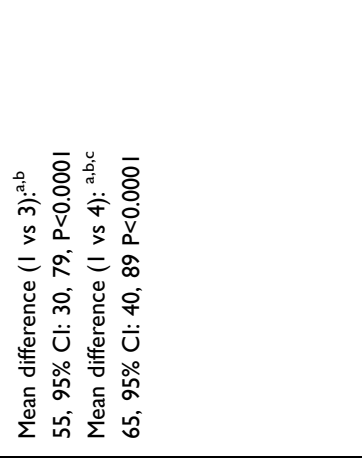 & 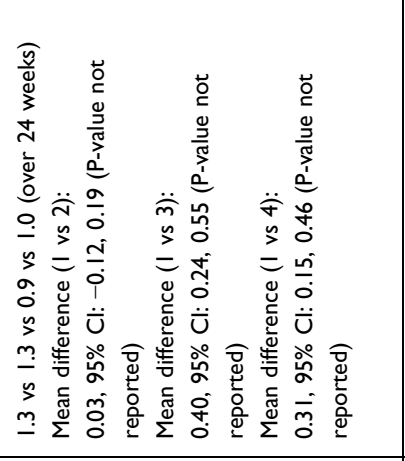 & 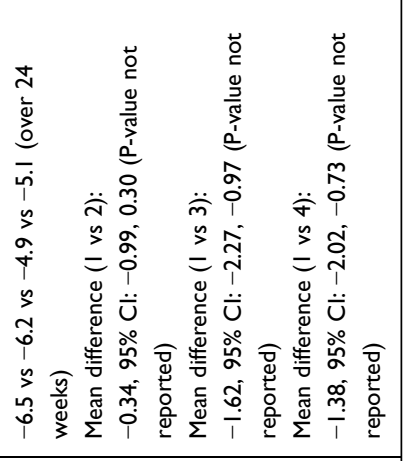 & 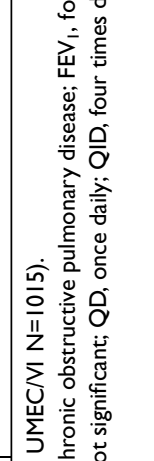 \\
\hline & 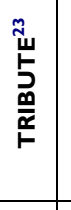 & $\begin{array}{l}\tilde{y} \\
\bar{y} \\
3 \\
\text { ñ }\end{array}$ & 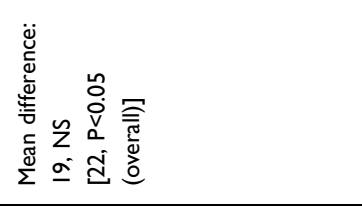 & $\frac{\mathscr{O}}{Z}$ & 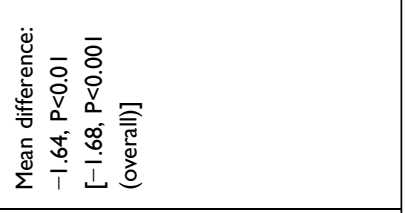 & 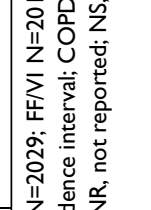 \\
\hline \multirow{4}{*}{ 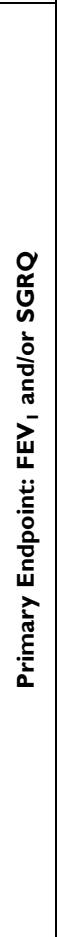 } & \multirow{2}{*}{ 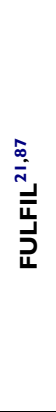 } & $\begin{array}{l}\frac{y}{d ँ} \\
\grave{d} \\
\text { กิ }\end{array}$ & 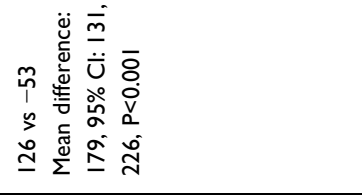 & 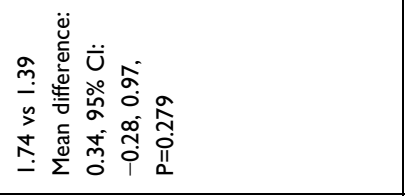 & 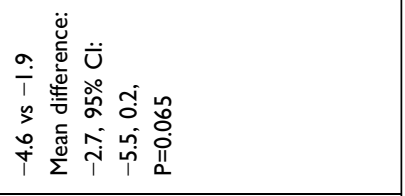 & 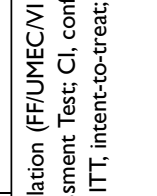 \\
\hline & & 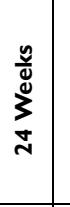 & 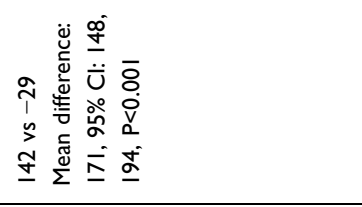 & 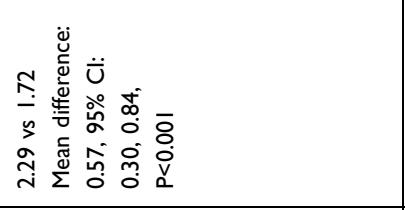 & 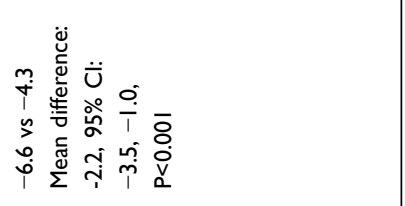 & 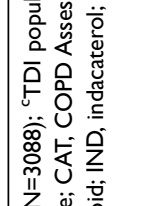 \\
\hline & $\begin{array}{l}\tilde{\tilde{y}} \\
\text { z } \\
0 \\
\underline{\tilde{z}}\end{array}$ & 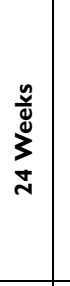 & 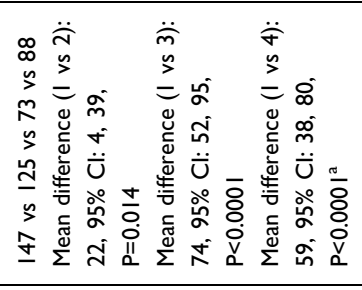 & 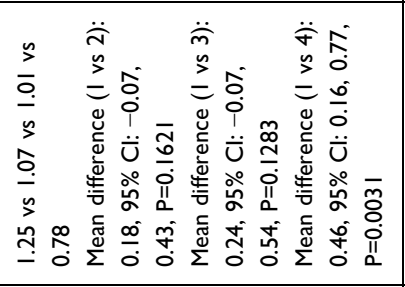 & 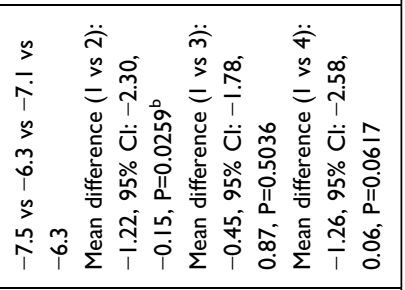 & 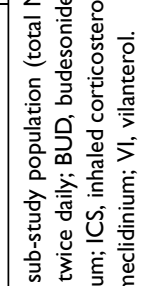 \\
\hline & 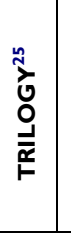 & $\begin{array}{l}\frac{y}{8} \\
\grave{\nu} \\
\text { ñ }\end{array}$ & 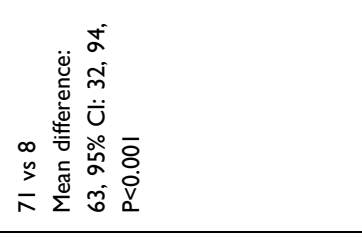 & 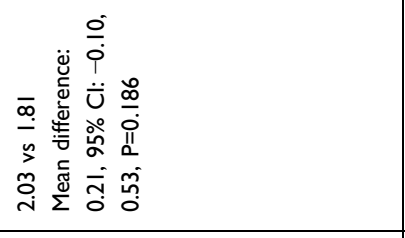 & 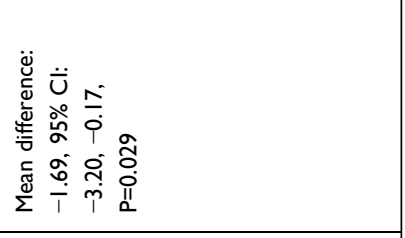 & 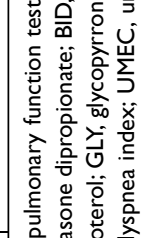 \\
\hline & & & 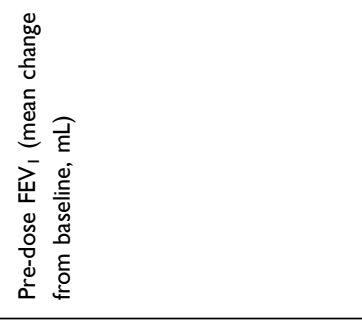 & 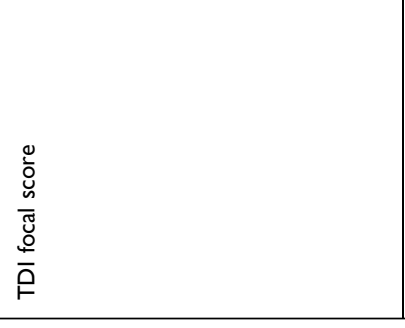 & 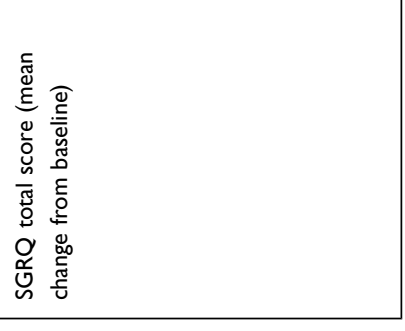 & 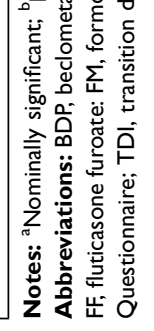 \\
\hline
\end{tabular}




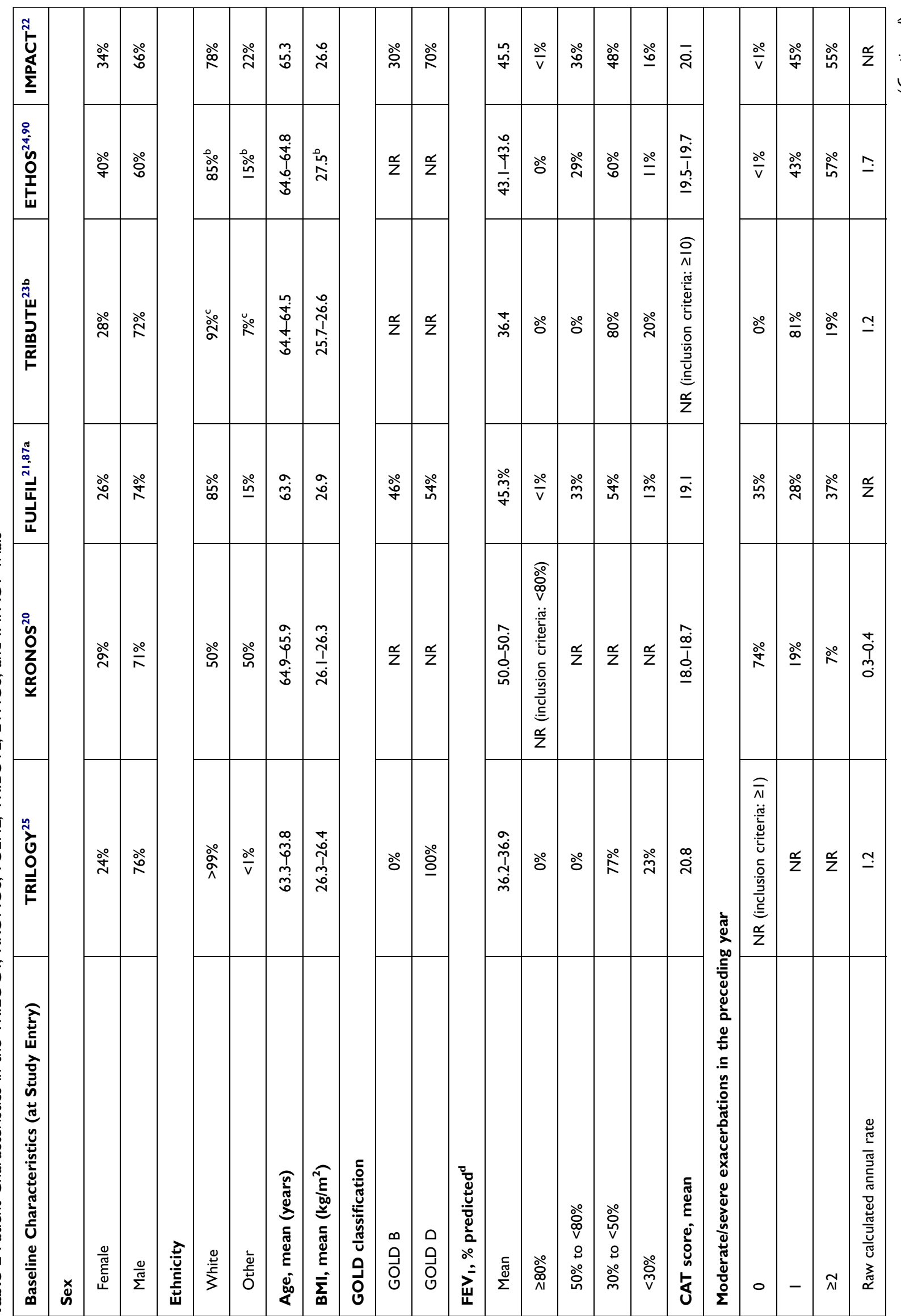


versus ICS/LABA over 24 weeks, and in FULFIL a $171 \mathrm{~mL}$ improvement at 24 weeks $(179 \mathrm{~mL}$ at 52 weeks; Table 1). There were generally no significant improvements in Transition Dyspnea Index (TDI) scores, except for the comparison of BUD/GLY/FM with openlabel BUD/FM in KRONOS (Table 1). Improvements in health-related quality of life measured by the St George's Respiratory Questionnaire (SGRQ) were seen in all trials, although results were not always statistically significant (Table 1). 20,21,25 Overall, data from these three trials demonstrated the lung function and health-related quality of life benefits with SITT versus ICS/LABA dual therapy in patients with symptomatic COPD.

The rate of moderate or severe exacerbations was a defined secondary endpoint in all three trials, although, in keeping with the patient population recruited, reported annual rates of exacerbations were low. Both TRILOGY and FULFIL reported significant reductions in moderate/severe exacerbation rates with SITT versus ICS/LABA (Table 1). ${ }^{21,25}$ In the KRONOS trial, there was a significant reduction in exacerbation rates with BUD/GLY/FM versus FM/GLY but not versus BUD/FM or open-label BUD/FM. ${ }^{20}$ Unusually, the raw exacerbation rate captured in the year before study entry was lower than the model-estimated exacerbation rate observed during the trial in all treatment arms; this was most notable in the FM/GLY arm ( 0.3 before study entry; 0.95 model-estimated at 24 weeks), where it increased to more than double the rate in the BUD/GLY/FM arm at the end of the trial ( 0.4 before study entry; 0.46 model-estimated at 24 weeks). ${ }^{20}$ This observation is unexpected and these data thus need to be interpreted with caution.

The incidence of pneumonia was evaluated in the safety analyses of all three trials. It is important to note that inferences regarding ICS-induced pneumonia risk need to take into account interactions with other risk factors. ${ }^{31}$ For example, a recent pooled analysis of studies in patients with COPD treated with ICS/LABA medications indicated that the only risk factor for ICS-induced pneumonia was a low body mass index $\left(<25 \mathrm{~kg} / \mathrm{m}^{2}\right){ }^{31}$ Previous studies have also shown that the highest risk factors for pneumonia are disease severity and exacerbation history (Figure 1). In the TRILOGY, KRONOS, and FULFIL trials, pneumonia rates were low and comparable with each SITT and comparator groups (Table 3). It is worth noting that these clinical trials assessed pneumonia 


\section{Adjusted OR for predictors of 5-year CAP risk}

(6,805 patients with complete data from retrospective observational study using a UK-based database cohort of 14,513 patients with COPD)

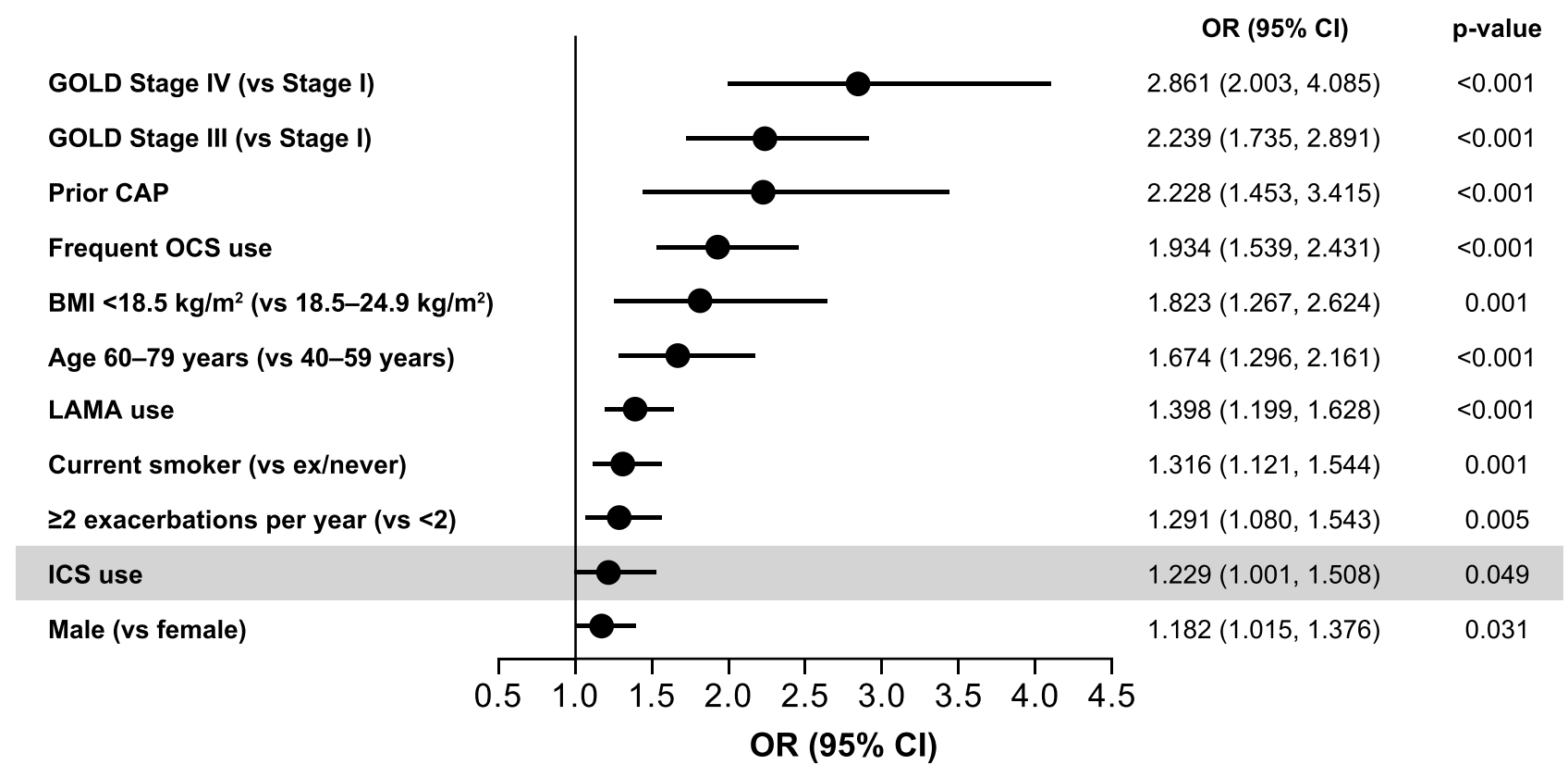

Figure I Disease severity and exacerbation history are strongly correlated with pneumonia risk whereas ICS only adds a small additional risk.

Abbreviations: BMI, body mass index; CAP, community-acquired pneumonia; Cl, confidence interval; COPD, chronic obstructive pulmonary disease; GOLD, Global Initiative for Chronic Obstructive Lung Disease; ICS, inhaled corticosteroid; LAMA, long-acting muscarinic antagonist; OCS, oral corticosteroid; OR, odds ratio. The graph has been independently created from the original data. ${ }^{49}$

in different ways, which limits cross-trial comparisons (Table 4).

\section{Trials with Exacerbation Reduction as the Primary Outcome}

Exacerbation rate was the primary endpoint in the TRIBUTE, IMPACT, and ETHOS trials (Table 1). In TRIBUTE, BDP/FM/GLY was compared with indacaterol (IND)/GLY over 52 weeks in 1532 patients with symptomatic COPD with severe or very severe airflow limitation $\left(\mathrm{FEV}_{1}<50 \%\right.$ predicted) and at least one moderate or severe exacerbation in the previous year (baseline characteristics for this and the other studies discussed in this section are provided in Table 2). ${ }^{23}$ Patients received one inhalation of IND/GLY per day during the run-in period (Table 1). ${ }^{23}$ The IMPACT trial compared FF/UMEC/VI with FF/VI and UMEC/VI over 52 weeks in 10,355 patients with symptomatic COPD and at least one exacerbation in the previous year $(55 \%$ had $\geq 2$ moderate or severe exacerbations [Table 2]). ${ }^{22}$ Patients continued on their COPD maintenance medication during the run-in period (Table 1), reflecting clinical practice. $^{22,32}$ The ETHOS trial compared BUD/GLY/FM, at two different doses of BUD (320 and $160 \mu \mathrm{g}$ ), with FM/GLY and BUD/FM over 52 weeks in 8509 patients with symptomatic COPD and a history of exacerbations $(57 \%$ had $\geq 2$ moderate or severe exacerbations [Table 2]). ${ }^{24}$ Patients discontinued maintenance medications during the run-in period, and received ipratropium bromide, which may have contributed to almost $50 \%$ of screened patients not being eligible for randomization (Table 1). ${ }^{24}$

In all studies, SITT reduced moderate/severe exacerbation rates and improved lung function and health-related quality of life (as measured by SGRQ total score) compared with dual therapies (Table 1). ${ }^{22-24}$ In TRIBUTE, BDP/FM/GLY reduced the annual rate of moderate/severe exacerbations by $15 \%$ versus IND/GLY. The observed exacerbation rate with each treatment was low, reflecting the characteristics of the patients recruited ( $81 \%$ of patients had one, and only $19 \%$ two or more, moderate or severe exacerbations in the preceding year). Compared with IND/GLY, BDP/FM/GLY also significantly improved SGRQ (difference -1.6 units) but did not significantly improve $\mathrm{FEV}_{1}$ at 52 weeks (difference $19 \mathrm{~mL}$ ). ${ }^{23} \mathrm{In}$ 


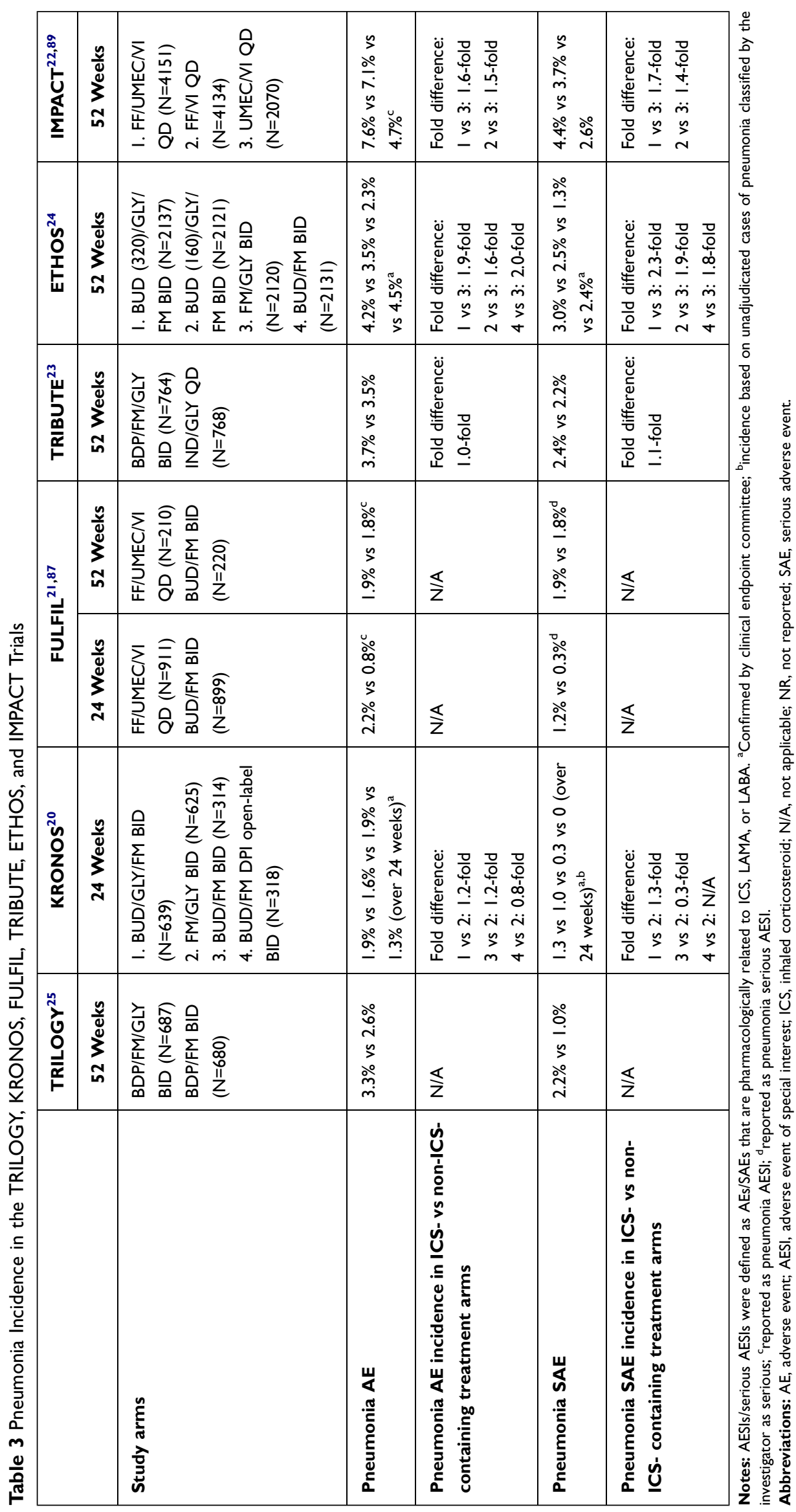




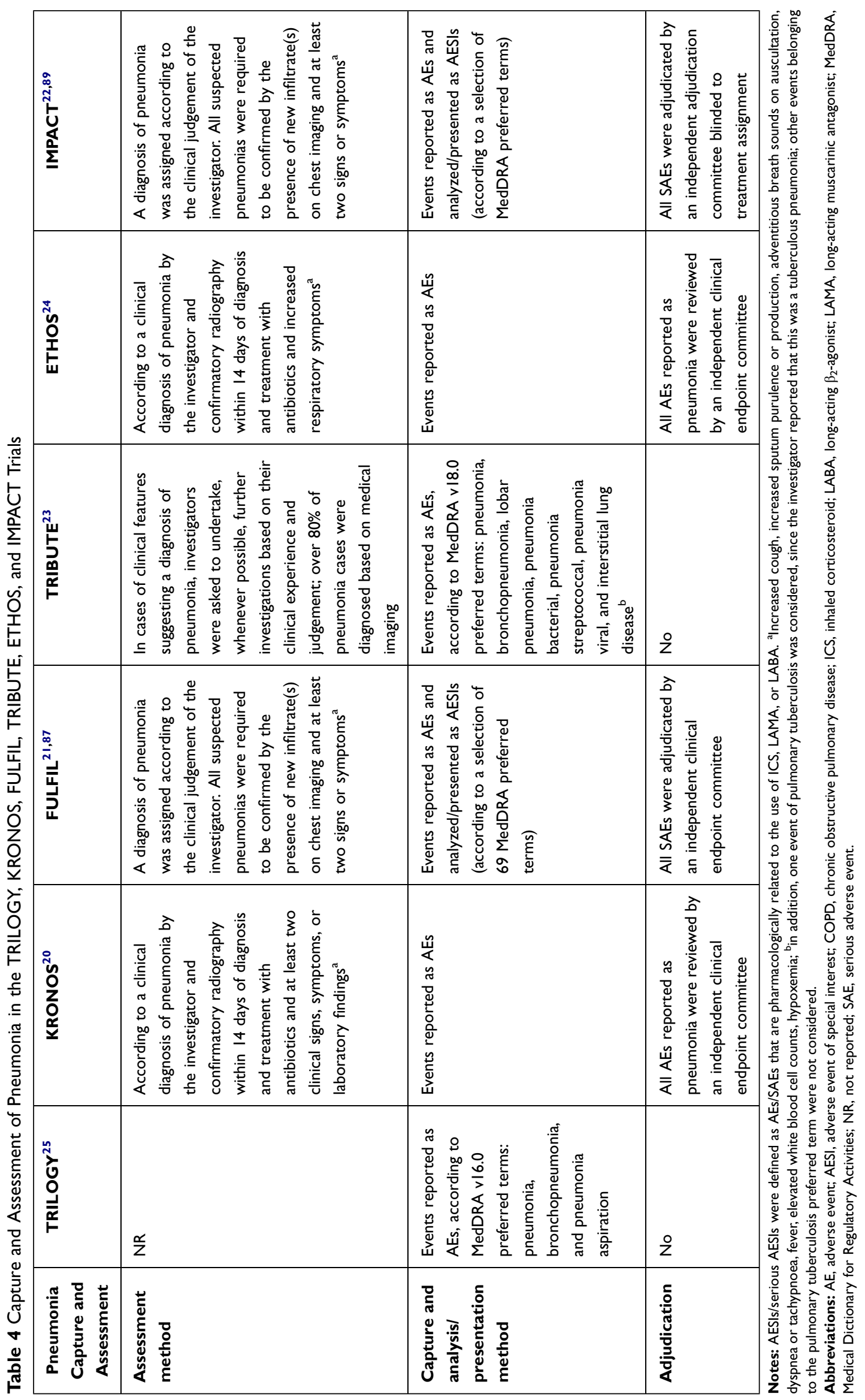


IMPACT, FF/UMEC/VI significantly reduced the annual rate of moderate or severe COPD exacerbations by $15 \%$ compared with FF/VI and by $25 \%$ compared with UMEC/VI. ${ }^{22}$ FF/UMEC/VI also significantly improved trough $\mathrm{FEV}_{1}$ (difference $97 \mathrm{~mL}$ vs FF/VI, $54 \mathrm{~mL}$ vs UMEC/VI) and SGRQ (difference -1.8 units vs each dual therapy). Recently published post hoc analyses of IMPACT show that the observed improvements in exacerbations, $\mathrm{FEV}_{1}$, and SGRQ with FF/UMEC/VI compared with UMEC/VI were not driven by abrupt ICS withdrawal in prior ICS users randomized to LAMA/LABA. ${ }^{32}$ In ETHOS, both BUD/GLY/FM arms led to a significant reduction in the annual rate of moderate or severe exacerbations (13-25\% reduction; Table 1). BUD 320 $\mu \mathrm{g}$ SITT also improved trough $\mathrm{FEV}_{1}$ compared with FM/GLY and BUD/FM (difference 55 and $65 \mathrm{~mL}$, respectively), and SGRQ total score (difference -1.6 and -1.4 units, respectively) (Table 1).

The incidence of pneumonia was evaluated in all three of these trials. Using the LAMA/LABA arm as a baseline in each of these studies, the results show no difference in pneumonia adverse event (AE) incidence in TRIBUTE between SITT and LAMA/LABA, a 1.6-fold difference in IMPACT and a 1.9-fold difference in ETHOS (for BUD $320 \mu \mathrm{g}$ SITT vs LAMA/LABA) (Table 3). Data were similar with regards to pneumonia serious AEs, with a 1.1-fold difference in TRIBUTE, 1.7-fold in IMPACT and 2.3-fold in ETHOS (for BUD $320 \mu \mathrm{g}$ SITT vs LAMA/LABA) (Table 3). ETHOS and IMPACT showed the clearest evidence for increased risk of pneumonia for ICS-containing medicines. ${ }^{22,24}$ This was most likely related to the severity of the patient populations and the size of the studies, and the relative increase in risk with ICS use was comparable to LAMA/LABA treatment arms. $^{22,24}$ Cross-trial comparisons should be interpreted with extreme caution due to differences in trial design, baseline population characteristics, definitions of pneumonia (adjudicated vs all reported; Table 4), and assessment of outcomes. This was recognized in a 2016 report from the European Medicines Agency (EMA)'s Pharmacovigilance Risk Assessment Committee (PRAC), which recognized pneumonia as a class effect of ICScontaining therapies in patients with COPD, with no conclusive evidence of intra-class differences. ${ }^{33}$ Similarly, a European public assessment report (EPAR) assessment report on $\mathrm{BDP} / \mathrm{FM} / \mathrm{GLY}$ published by the EMA in December 2018 concluded that: Differences in study design, methodology for confirming the diagnosis of pneumonia, sample size and populations assessed ... do not allow drawing meaningful conclusions of whether Trimbow ${ }^{\circledR}$ has a more favorable benefit/risk profile ... than the triple combination [FF/UMEC/VI] assessed in the IMPACT study. ${ }^{34}$

\section{Head-to-Head Trials of Triple Therapy with Different ICS Components}

While it remains very difficult to make cross-trial comparisons, head-to-head trials comparing different ICScontaining treatments in the same population help to understand benefit and risk. The TRISTAR trial compared SITT using BDP/FM/GLY with multiple-inhaler triple therapy in the form of FF/VI plus tiotropium (TIO) as the comparator group. ${ }^{35}$ The study was conducted over 26 weeks in 1157 patients with symptomatic COPD with severe or very severe airflow limitation and at least one exacerbation in the preceding year. Results showed that both triple therapies had comparable benefit and risk profiles. BDP/FM/GLY was non-inferior to FF/VI plus TIO for the primary endpoint of change from baseline in SGRQ total score at Week 26, with improvements of -6.77 and -7.82 units, respectively. ${ }^{35}$ Improvements in trough $\mathrm{FEV}_{1}$ at Week 26 were greater with FF/VI plus TIO (109 mL) compared with BDP/FM/GLY $(59 \mathrm{~mL})$, and rates of moderate and severe exacerbations over the 26 weeks of treatment were low and comparable between the treatment arms $(0.516$ for BDP/FM/GLY and 0.474 for FF/VI plus TIO). ${ }^{35}$ Similar rates of serious AEs of pneumonia (captured using the preferred terms of bronchopneumonia, lobar pneumonia, pneumonia, and pneumonia staphylococcal) were reported for BDP/FM/GLY (1.4\%) and $\mathrm{FF} / \mathrm{VI}$ plus TIO $(1.9 \%){ }^{35}$

Two different ICS-containing treatments were also compared in the FULFIL trial. As discussed above, FF/UMEC/VI significantly improved $\mathrm{FEV}_{1}$ and SGRQ total score and reduced exacerbations at 24 weeks compared with BUD/FM. ${ }^{21}$ The rate of pneumonia AEs of special interest (AESIs; defined as AEs that are pharmacologically related to the use of ICS, LAMA or LABA) was $2 \%$ with FF/UMEC/VI and $1 \%$ with BUD/FM at 24 weeks and was $2 \%$ for both treatments at 52 weeks. Thus, in both FULFIL and TRISTAR, pneumonia rates were comparable between treatment arms.

\section{Hospitalizations and All-Cause Mortality}

Patients with COPD account for approximately onequarter of all hospitalizations. ${ }^{36}$ Severe exacerbations of COPD leading to hospitalization are associated with 
substantial mortality and risk of recurrence, with the risk of death highest after a hospitalization and increasing with the frequency of such events. ${ }^{11,37-40}$ Reducing exacerbation-related hospitalizations is an essential treatment goal for many patients with COPD. Typically, clinical trials have focused on the incidence of moderate and severe exacerbations combined (data for which have already been described); however, trials conducted in a population of patients at high risk of exacerbation, such as TRIBUTE, IMPACT, and ETHOS, have also assessed severe exacerbations (events leading to hospitalization or death) separately. ${ }^{22-24}$ Two of these trials, IMPACT and ETHOS, also assessed the risk of all-cause mortality as a pre-specified endpoint. ${ }^{22,24}$

In TRIBUTE, there was a non-significant reduction in the rate of severe exacerbations with BDP/FM/GLY SITT compared with IND/GLY (Table 5). ${ }^{23}$ In the ETHOS trial, BUD $320 \mu \mathrm{g}$ SITT significantly reduced severe exacerbation rates versus $\mathrm{BUD} / \mathrm{FM}$ ( $20 \%$ relative reduction) but not versus FM/GLY ( $16 \%$ relative reduction; $P=0.09$ ); none of the comparisons between BUD $160 \mu \mathrm{g}$ SITT and dual therapies were statistically significant (Table 5). ${ }^{24}$ In IMPACT, SITT with FF/UMEC/VI significantly reduced the annual rate of severe exacerbations compared with UMEC/VI (34\% relative reduction), but not FF/VI (13\% relative reduction; $P=0.06$ ) (Table 5 ). ${ }^{22}$

All-cause mortality was not a pre-specified outcome in the TRIBUTE trial; incidence of AEs leading to death was $2 \%$ in the BDP/FM/GLY arm and $3 \%$ in the IND/GLY arm. ${ }^{23}$ A post hoc pooled analysis evaluated all fatal AEs reported in the TRILOGY, TRINITY, and TRIBUTE trials. ${ }^{26} \mathrm{~A}$ non-significant trend was observed for reduced risk of a fatal $\mathrm{AE}$ in patients with severe/very severe COPD at increased risk for exacerbations who received ICS-containing versus non-ICS-containing treatments (29\% relative risk reduction $[0.71 \%$ absolute risk reduction]; $P=0.066$ ). A similar non-significant reduction in fatal AEs was seen for BDP/FM/GLY SITT versus nonICS treatments (28\% relative risk reduction [0.69\% absolute risk reduction]; $P=0.096){ }^{26}$ These findings, however, should be interpreted with caution for several reasons: mortality was not a pre-specified endpoint in any of the studies; follow-up was incomplete; the absence of a nonICS arm in TRILOGY; the majority of patients (58\%) in the pooled comparator group received only LAMA and not dual therapy; and the analysis was based on the number of patients with AEs that led to a fatal outcome rather than on fatal events.
The TORCH and SUMMIT trials, both powered for the primary outcome of all-cause mortality, failed to show a statistically significant benefit on survival for ICS/LABA compared with placebo, despite fewer deaths with ICS/LABA. ${ }^{41,42}$ However, there are key differences in study population between these earlier studies and the more recent studies of SITTs that should be taken into consideration when evaluating the potential value of ICS in reducing mortality. TORCH recruited patients with a pre-bronchodilator $\mathrm{FEV}_{1}<60 \%$ predicted and postbronchodilator increase in $\mathrm{FEV}_{1} \%$ predicted $<10 \%$, while SUMMIT recruited those with moderate airflow limitation ( $\mathrm{FEV}_{1} 50-70 \%$ predicted) and a history or increased risk of cardiovascular disease; in neither study was a history of exacerbations required, which is a major difference in the patients enrolled in these studies compared with the more recent IMPACT and ETHOS trials.

All-cause mortality was prospectively examined as a pre-specified endpoint in both the IMPACT and ETHOS trials. In IMPACT, FF/UMEC/VI significantly reduced the risk of all-cause on-treatment mortality by $42 \%$ compared with UMEC/VI in patients with symptomatic COPD and at high risk of exacerbations (absolute risk reduction: $0.68 \%){ }^{22}$ The inclusion of off-treatment deaths showed a significant $29 \%$ reduction in the risk of all-cause mortality with FF/UMEC/VI (Table 5). ${ }^{22}$ These findings have since been confirmed in a recent post hoc analysis following the collection of additional vital status data, which provides vital status at nominal Week 52 for $99.6 \%$ of the intent-to-treat population and identified 27 additional off-treatment deaths. ${ }^{43}$ The data were consistent with the original analysis and showed a $28 \%$ reduction in the risk of on-/off-treatment all-cause mortality with $\mathrm{FF} / \mathrm{UMEC} / \mathrm{VI}$ versus UMEC/VI $(P=0.042$; absolute risk reduction $0.83 \%) .{ }^{43}$ This demonstrates the robustness of the reduction in all-cause mortality originally reported in IMPACT. These findings are now also supported by those from the ETHOS study, in which BUD $320 \mu \mathrm{g}$ SITT reduced the risk of on-/off-treatment all-cause mortality by $46 \%$ versus $\mathrm{FM} / \mathrm{GLY}$ (absolute risk reduction: 1.0\%; Table 5). There was no reduction in all-cause mortality risk with BUD $160 \mu \mathrm{g}$ SITT versus either dual-therapy comparator arms (Table 5). The consistency of effect on severe exacerbation and all-cause mortality observed in IMPACT with FF/UMEC/VI versus UMEC/VI was not seen in ETHOS, with BUD $320 \mu \mathrm{g}$ SITT not leading to a statistically significant reduction in severe exacerbations compared with FM/GLY; it is the severe exacerbations 


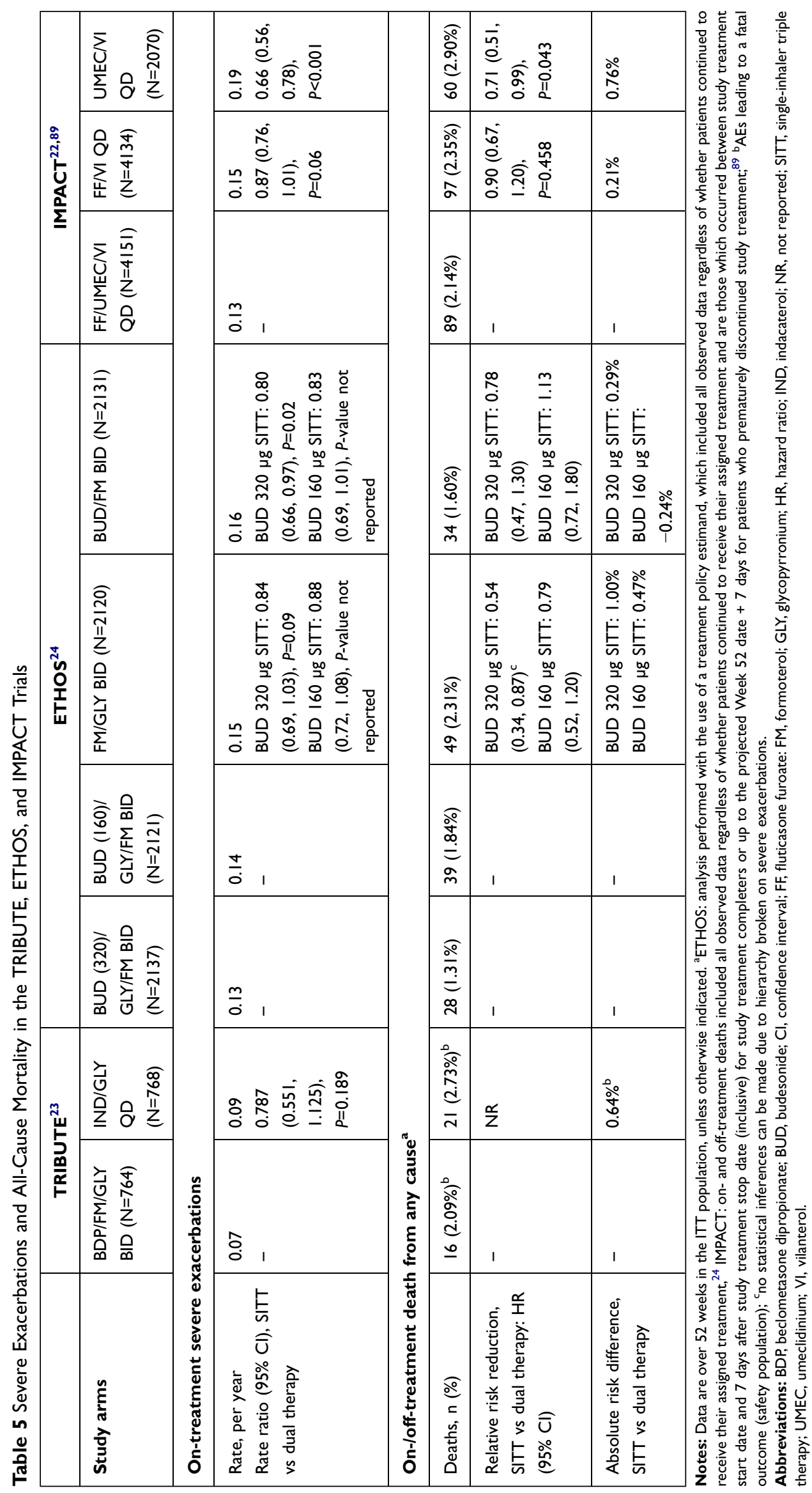




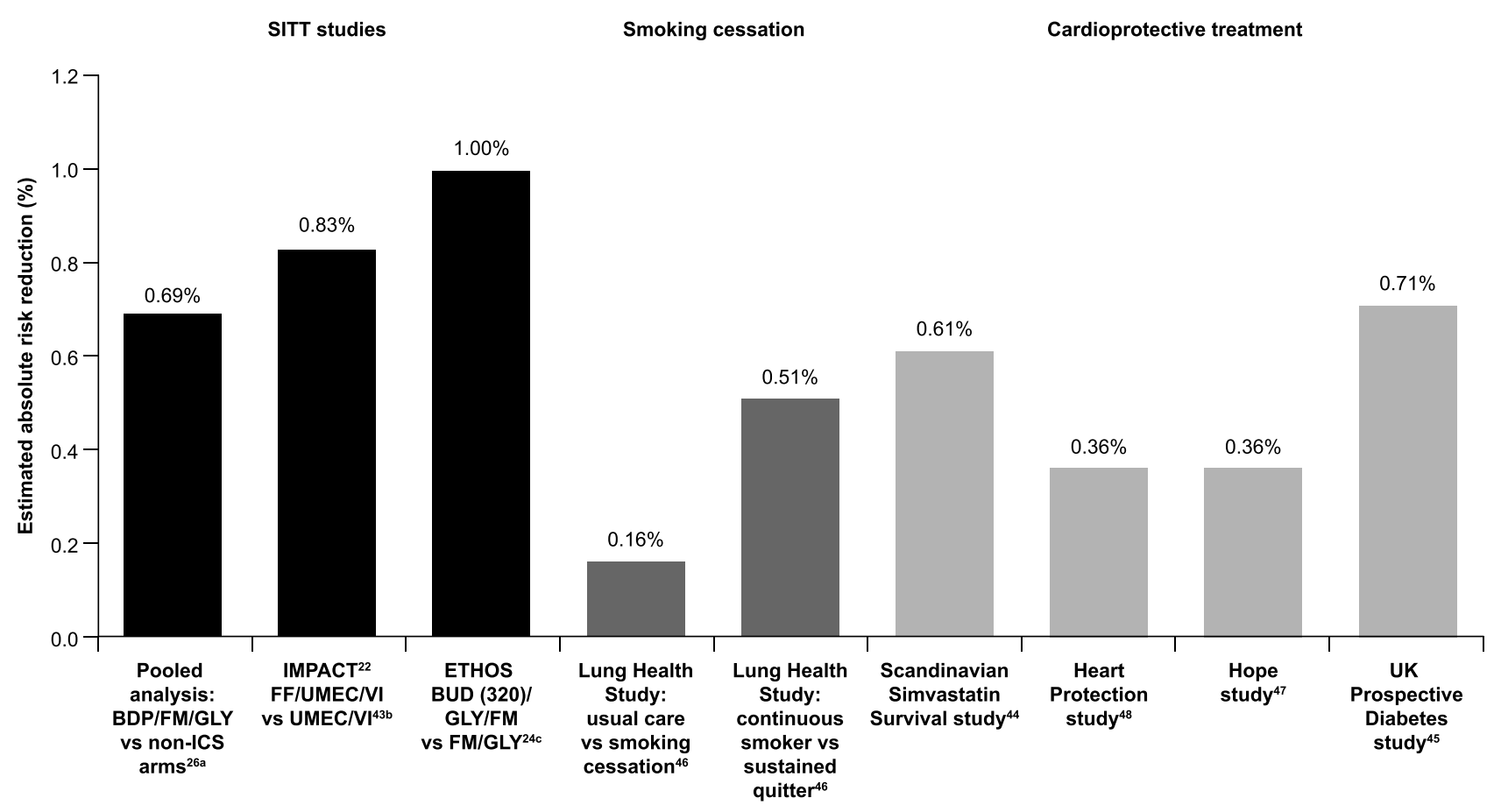

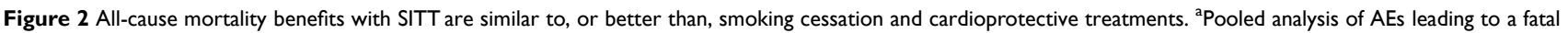
outcome (safety population); bon- and off-treatment deaths in post hoc analysis with additional vital status follow-up (vital status available for $99.6 \%$ of patients at nominal Week 52); ' analysis included all observed data regardless of whether patients continued to receive their assigned treatment.

Abbreviations: BDP, beclometasone dipropionate; BUD, budesonide; FF, fluticasone furoate: FM, formoterol; GLY, glycopyrronium; ICS, inhaled corticosteroid; IND, indacaterol; SITT, single-inhaler triple therapy; UMEC, umeclidinium; VI, vilanterol. The graph has been independently created from the original data.

leading to hospitalization that increase the risk of mortality. ${ }^{11,40}$ Both IMPACT and ETHOS provide supporting evidence of the role of ICS in reducing all-cause mortality risk for patients with symptomatic COPD at high risk of exacerbations. The absolute risk reductions, while apparently small, are similar to, or better than, those seen in studies of smoking cessation or cardioprotective treatments (Figure 2). ${ }^{44-48}$

\section{Benefit versus Risk with SITT}

In 2016, the EMA directed the PRAC to evaluate the benefit/risk balance of ICS-containing medicinal products for the treatment of patients with COPD. The PRAC concluded that while patients with COPD treated with ICS are at increased risk of pneumonia (an established risk associated with ICS use) the benefits of ICS continue to outweigh their risk. ${ }^{33}$ Furthermore, there was no conclusive evidence of differences in this risk for different ICScontaining products (BDP, BUD, FF, FP or flunisolide).

Exacerbation history is one of the significant driving factors for pneumonia risk (Figure 1) ${ }^{49}$ and this may be a factor in the differential incidences of pneumonia observed in the TRILOGY, KRONOS, FULFIL, TRIBUTE, ETHOS, and IMPACT trials. ${ }^{20-25}$ Principal eligibility criteria in these studies (Table 1) were largely similar: patients were 40 years or older, current or former smokers and had symptomatic COPD (COPD Assessment Test [CAT] score $\geq 10) .{ }^{20-25}$ However, there were substantial differences in the exacerbation history of patients. At baseline, $74 \%$ of patients randomized in KRONOS and $35 \%$ in FULFIL had no exacerbations in the preceding year (Table 2). In contrast, enrollment criteria meant that $<1 \%$ of the study population in both ETHOS and IMPACT had no exacerbations in the preceding year ( $43 \%$ and $45 \%$ had one, and $57 \%$ and $55 \%$ had $\geq 2$ exacerbations, respectively; Table 2). In TRIBUTE, $81 \%$ of patients had experienced one exacerbation in the preceding year, with $19 \%$ experiencing $\geq 2$ exacerbations (Table 2).

There were also differences in other characteristics at baseline, such as patients' prior receipt of ICS-containing triple therapy and lung function status $\left(\mathrm{FEV}_{1 \%}\right.$ predicted) (Table 2). It is worth noting that some of these differences relate to patients' characteristics that may influence the risk of pneumonia events. ${ }^{31}$ Other notable differences between the studies included the definition and assessment methods used to capture AEs such as pneumonia (Table 4). The absolute rate of pneumonia thus differs between study 
populations and definition criteria used (including the use or not of independent adjudication) but, in general, ICS approximately doubles the risk of pneumonia compared with non-ICS-containing regimens, as evidenced in multiple studies of SITT $^{22,24,50}$ and ICS/LABA. ${ }^{41,42,51-57}$ Overall, baseline characteristics of patient populations are a key consideration for discussions about both efficacy and safety to aid clinicians in their treatment decision-making.

Tighter monitoring of the collection of safety data and differences in the definitions, method of assessment and independent adjudication of events, such as pneumonia, may influence the safety profile reported in different studies. The use in trials of broader definitions of pneumonia that do not rely on independent adjudication is more representative of routine clinical practice. Even so, pneumonia is a heterogenous event with considerable clinical overlap with COPD exacerbations. ${ }^{58}$ Differentiating between these two events poses significant challenges. ${ }^{58-61}$ Both hospitalization due to severe exacerbations and pneumonia have a profound impact on patient outcomes, supporting the idea that clinical trials should evaluate these events together as a composite outcome of hospitalized respiratory events, as recently reported for the IMPACT trial. ${ }^{62}$ In that trial, triple therapy with FF/UMEC/VI resulted in a significant $17 \%$ reduction in the risk of a severe exacerbation or hospitalized pneumonia compared with UMEC/VI $(P=0.011){ }^{62}$ Ultimately, the key is to identify patients with COPD who will have a favorable benefit/risk ratio with triple therapy.

\section{ICS Responsiveness and Eosinophils}

Identifying which patients are most likely to respond to ICS (and other treatments) is important to maximize the benefit/risk ratio and move toward a personalized medicine approach for COPD. ${ }^{63} \mathrm{~A}$ recent post hoc analysis of three RCTs reported that only smoking history and blood eosinophil count were independent predictors of response to ICS (BUD/FM vs FM) in patients with severe or very severe COPD and a history of exacerbations. ${ }^{63}$ This analysis showed that the relationship between blood eosinophil count and likely response to ICS is a continuum and not dichotomous. ${ }^{63}$ An analysis of data from the IMPACT trial also modelled the relationship between blood eosinophil count as a continuous variable and ICS effects. ${ }^{64}$ Consistent with previous findings, ${ }^{63}$ this analysis of IMPACT showed that the response to ICS-containing therapy was modulated by both blood eosinophil count and smoking status. ${ }^{64}$ The benefits of ICS-containing treatments in terms of reduction in rates of moderate/ severe and severe exacerbations increased with increasing blood eosinophil counts. ${ }^{64}$ This was seen for both $\mathrm{FF} / \mathrm{UMEC} / \mathrm{VI}$ and FF/VI compared with UMEC/VI, ${ }^{64}$ indicating that the relationship between blood eosinophil count and exacerbation reduction is independent of background bronchodilation. This relationship was modulated by smoking status, with greater benefits seen in former versus current smokers at all blood eosinophil counts. ${ }^{64}$ This post hoc analysis emphasizes the importance of smoking cessation, with the observation that current smokers with lower blood eosinophil count $(<200$ cells $/ \mu \mathrm{L})$ showed no benefit of SITT over LAMA/LABA, while benefits were seen across the blood eosinophil continuum in former smokers. ${ }^{64}$

The GOLD 2020 Report now includes therapeutic recommendations for blood eosinophil counts and advises that thresholds of $<100$ cells $/ \mu \mathrm{L}$ and $\geq 300$ cells $/ \mu \mathrm{L}$ can be used to identify patients with a low likelihood and the greatest likelihood of benefiting from ICS-containing therapies, respectively. ${ }^{3}$ However, recent analyses highlight that blood eosinophil count should be viewed as a continuum and evaluated in the context of other risk factors for exacerbations, and cut-offs should not be regarded as explicit. ${ }^{63-65}$

It is important to note that these eosinophil data are from large studies and reported at mean treatment group level, and the implications of population-based findings at the individual patient level remain to be established.

\section{Implications for Patient Management}

Current GOLD treatment recommendations advocate approaches to the treatment and management of COPD that aim to reduce symptom burden and risk of future exacerbations. ${ }^{3}$ Following a review of a patient's response to treatment initiation, adjustments in pharmacological treatment may be needed. After checking inhaler technique and compliance, treatment can be escalated/de-escalated based on the presence of the predominant symptoms of breathlessness and exercise limitation, and the continued occurrence of exacerbations whilst on maintenance therapy. Any change in treatment should always be undertaken under close medical supervision and considering whether there is a lack of clinical benefit and/or presence of side effects. Patients with COPD and their doctors should be 
alert for signs and symptoms of pneumonia, bearing in mind that the clinical features of pneumonia overlap with those of exacerbations of the underlying disease. ${ }^{33}$ This fact necessitates a more detailed exploration of the overlap of hospitalized respiratory events in future COPD trials.

Studies indicate that most patients with COPD would benefit from optimal bronchodilation with a combination of a LAMA and a LABA. Dual LAMA/LABA therapy has demonstrated improvements in patient outcomes compared with either agent used alone, including in symptomatic patients at low exacerbation risk not using concurrent ICS and those naivve to COPD maintenance therapy. ${ }^{66-79}$ For patients with high risk of exacerbations and those who remain symptomatic despite treatment with LAMA/LABA combination therapy, the additional use of ICS should be considered, informed by the use of biomarkers such as blood eosinophils in conjunction with other clinical factors. As COPD is a progressive disease, ICS withdrawal should only be considered if there are adverse effects that seem to outweigh potential benefits, with particular caution in patients with blood eosinophil counts $\geq 300$ cells $/ \mu \mathrm{L}$, who are at greatest risk of experiencing a relapse of exacerbations. ${ }^{3}$

Inappropriate prescribing of triple therapy, or, in some cases, lack thereof when clinically indicated, ${ }^{18}$ may in part be due to confusion among healthcare professionals given the increasing number of medications, combinations, and inhaler devices available. ${ }^{80}$

Severe exacerbations resulting in hospitalization are key events for patients, with profound clinical implications. These include accelerated lung function decline, worsening of health-related quality of life, increased comorbidities, and significantly increased mortality. ${ }^{9-11}$ Estimates suggest a survival rate of less than $50 \%$ at 5 years after hospitalization from a severe exacerbation. ${ }^{38}$ The importance of preventing exacerbation-related hospitalizations and mortality should therefore be at the forefront of treatment and management strategies and, from recent evidence, SITT has a key role in these strategies and for improving overall patient outcomes. As a key driver of COPD-related healthcare costs, reducing severe exacerbations is also essential for reducing the substantial socioeconomic burden associated with COPD. ${ }^{6,11,81}$ More studies in the usual care setting are required to better document the benefits and potential harms of therapy in the wider COPD population and to determine whether patients in routine practice are achieving expected outcomes.

In the appropriate patients, SITT also has a potential role to play in terms of simplifying treatment regimens, thereby potentially improving treatment adherence and patient outcomes. Until recently, triple therapy required the use of multiple inhalers, sometimes several times per day. ${ }^{80}$ Compared with single-inhaler use, the use of multiple inhalers has been shown to be associated with poorer persistence and adherence to COPD medication, which could, in turn, lead to poor symptom control, higher healthcare utilization and costs, and reductions in healthrelated quality of life. ${ }^{82-85}$ The randomized, Phase IV effectiveness INTREPID study (NCT03467425) provides supporting evidence for the benefits of single- versus multiple-inhaler triple therapy. ${ }^{86}$ The study evaluated SITT with $\mathrm{FF} / \mathrm{UMEC} / \mathrm{VI}$ versus multiple-inhaler triple therapy as a class over 24 weeks, in 3092 patients with symptomatic COPD and a history of exacerbations who were already receiving triple therapy or had a documented clinical indication for escalation from dual to triple therapy. ${ }^{86}$ This study showed that, in usual clinical care, SITT with $\mathrm{FF} / \mathrm{UMEC} / \mathrm{VI}$ resulted in a significantly greater proportion of patients achieving clinically relevant health status improvements, and significantly improved lung function (in a subset of the overall population), compared with multiple-inhaler triple therapy, with a similar safety profile, including the incidence of pneumonia serious AEs. ${ }^{86}$

\section{Conclusions}

Current evidence from recent RCTs of SITT compared with ICS/LABA and LAMA/LABA dual therapies confirms the benefits of SITT for symptomatic patients at high risk of exacerbations. The key benefits of SITT are significant reductions in exacerbations and hospitalizations, with encouraging data suggesting a reduction in all-cause mortality, which should be weighed against a higher incidence of study-reported pneumonia with ICS-containing treatment regimens. Beyond the benefits of reducing exacerbations, there are improvements in lung function and patient-reported outcomes. Treatment of COPD should follow an approach that weighs benefit versus risk at the individual patient level. Optimizing and simplifying treatment as early as possible in the course of the disease to prevent exacerbations, and their complications, and improve quality of life and adherence is critical for maximizing long-term benefits and patient outcomes. Avoiding therapies that are unlikely to be of benefit to an individual is also essential. Identifying and using the right treatment, for the right patient, at the right time should underpin the treatment and management of patients with COPD. If this is done, it will lead to better outcomes for patients. 


\section{Abbreviations}

AE, adverse event; BDP, beclometasone dipropionate; BUD, budesonide; COPD, chronic obstructive pulmonary disease; CAT, COPD Assessment Test; DPI, dry powder inhaler; EMA, European Medicines Agency; EPAR, European public assessment report; FF, fluticasone furoate; $\mathrm{FEV}_{1}$, forced expiratory volume in 1 second; FM, formoterol fumarate; GLY, glycopyrronium bromide; IND, indacaterol; ICS, inhaled corticosteroid; LAMA, long-acting muscarinic antagonist; LABA, long-acting $\beta_{2}$-agonist; PRAC, Pharmacovigilance Risk Assessment Committee; RCTs, randomized controlled trials; SITT, single-inhaler triple therapy; SGRQ, St George's Respiratory Questionnaire; UMEC, umeclidinium; VI, vilanterol.

\section{Acknowledgments}

Editorial support (in the form of writing assistance, collating author comments, assembling tables/figures, grammatical editing, fact checking, and referencing) was provided by Carol A. Richter, PhD, of Gardiner-Caldwell Communications (Macclesfield, UK) and Chrystelle Rasamison, at Fishawack Indicia Ltd. part of Fishawack Health, UK, and was funded by GlaxoSmithKline (GSK).

\section{Author Contributions}

All authors made a significant contribution to the work reported, whether the contribution was in the conception/ design of this analysis, acquisition of the data, or analysis and interpretation of the data; took part in drafting, revising and critically reviewing the manuscript, and approved the final version of the manuscript before submission to an agreed upon journal. All authors agree to be accountable for all aspects of the work.

\section{Funding}

Editorial support (in the form of writing assistance, collating author comments, assembling tables/figures, grammatical editing, fact checking, and referencing) was provided by Carol A. Richter, $\mathrm{PhD}$, of Gardiner-Caldwell Communications (Macclesfield, UK) and Chrystelle Rasamison, at Fishawack Indicia Ltd. part of Fishawack Health, UK, and was funded by GlaxoSmithKline (GSK).

\section{Disclosure}

J. Bourbeau reports grants from CIHR and Canadian Respiratory Research Network (CRRN), Foundation of the McGill University Health Center, Aerocrine, AstraZeneca,
Boehringer Ingelheim, Grifols, GSK, Novartis, and Trudell; personal conference and advisory board fees from Canadian Thoracic Society, CHEST, Astra Zeneca, Boehringer Ingelheim, Grifols, GSK, Novartis, and Trudell. M. Bafadhel reports grants from AstraZeneca; advisory board attendance for AstraZeneca, Chiesi, Boehringer Ingelheim, and GSK; attendance at educational meetings facilitated by AstraZeneca, Chiesi, and Boehringer Ingelheim; and scientific advisor for ProAxsis and AlbusHealth. C. Compton, P.W. Jones, N.C. Barnes, D.A. Lipson, V. Di Boscio, and G. Weiss are employees of GSK and hold stocks and shares in GSK. N. Martin was an employee of GSK at the time the study was conducted. D.M.G. Halpin has received personal fees from AstraZeneca, Boehringer Ingelheim, Chiesi, GSK, Novartis, Pfizer, and Sanofi and non-financial support from Boehringer Ingelheim and Novartis. The authors report no other conflicts of interest in this work.

\section{References}

1. World Health Organization. Health statistics and information systems: projections of mortality and causes of death, 2016 to 2060; 2016. Available from: https://www.who.int/healthinfo/global_bur den disease/projections/en/. Accessed February 11, 2021.

2. Fletcher MJ, Upton J, Taylor-Fishwick J, et al. COPD uncovered: an international survey on the impact of chronic obstructive pulmonary disease [COPD] on a working age population. BMC Public Health. 2011;11(1):612. doi:10.1186/1471-2458-11-612

3. Global Initiative for Chronic Obstructive Lung Disease (GOLD). Global Strategy for the Diagnosis, Management, and Prevention of Chronic Obstructive Pulmonary Disease. 2020 Report. 2020; Available from: https://goldcopd.org/. Accessed February 11, 2021.

4. Guarascio AJ, Ray SM, Finch CK, Self TH. The clinical and economic burden of chronic obstructive pulmonary disease in the USA.. Clinicoecon Outcomes Res. 2013;5:235-245. doi:10.2147/CEOR. S34321

5. Miller JD, Foster T, Boulanger L, et al. Direct costs of COPD in the U.S.: an analysis of Medical Expenditure Panel Survey (MEPS) data. COPD. 2005;2(3):311-318.

6. Miravitlles M, Murio C, Guerrero T, Gisbert R. EPOC DSGDsAyFel. Pharmacoeconomic evaluation of acute exacerbations of chronic bronchitis and COPD. Chest. 2002;121(5):1449-1455.

7. Strassels SA, Smith DH, Sullivan SD, Mahajan PS. The costs of treating COPD in the United States. Chest. 2001;119(2):344-352.

8. Anees UR, Ahmad Hassali MA, Muhammad SA, et al. The economic burden of chronic obstructive pulmonary disease (COPD) in the USA, Europe, and Asia: results from a systematic review of the literature. Expert Rev Pharmacoecon Outcomes Res. 2019:1-12.

9. Chenna PR, Mannino DM. Outcomes of severe COPD exacerbations requiring hospitalization. Semin Respir Crit Care Med. 2010;31 (3):286-294.

10. Halpin DM, Decramer M, Celli C, Kesten S, Liu L, Tashkin DP. Exacerbation frequency and course of COPD. Int J Chron Obstruct Pulmon Dis. 2012;7:653-661. doi:10.2147/COPD.S34186

11. Halpin DM, Miravitlles M, Metzdorf N, Celli B. Impact and prevention of severe exacerbations of COPD: a review of the evidence. Int J Chron Obstruct Pulmon Dis. 2017;12:2891-2908. doi:10.2147/ COPD.S139470 
12. Brusselle G, Price D, Gruffydd-Jones K, et al. The inevitable drift to triple therapy in COPD: an analysis of prescribing pathways in the UK.. Int J Chron Obstruct Pulmon Dis. 2015;10:2207-2217. doi:10.2147/COPD.S91694

13. Chalmers JD, Tebboth A, Gayle A, Ternouth A, Ramscar N. Determinants of initial inhaled corticosteroid use in patients with GOLD A/B COPD: a retrospective study of UK general practice. NPJ Prim Care Respir Med. 2017;27(1):43. doi:10.1038/s41533-017-0040-Z

14. Fitch K, Iwasaki K, Pyenson B, Plauschinat C, Zhang J. Variation in adherence with Global Initiative for Chronic Obstructive Lung Disease (GOLD) drug therapy guidelines: a retrospective actuarial claims data analysis. Curr Med Res Opin. 2011;27(7):1425-1429. doi:10.1185/03007995.2011.583230

15. Gruffydd-Jones K, Brusselle G, Jones R, et al. Changes in initial COPD treatment choice over time and factors influencing prescribing decisions in UK primary care: a real-world study. NPJ Prim Care Respir Med. 2016;26(1):16002. doi:10.1038/npjpcrm.2016.2

16. Hurst JR, Dilleen M, Morris K, Hills S, Emir B, Jones R. Factors influencing treatment escalation from long-acting muscarinic antagonist monotherapy to triple therapy in patients with COPD: a retrospective THIN-database analysis. Int $J$ Chron Obstruct Pulmon Dis. 2018;13:781-792. doi:10.2147/COPD.S153655

17. Price D, West D, Brusselle G, et al. Management of COPD in the UK primary-care setting: an analysis of real-life prescribing patterns. Int J Chron Obstruct Pulmon Dis. 2014;9:889-904. doi:10.2147/ COPD.S62750

18. Halpin DMG, de Jong HJ, Carter V, Skinner D, Price D. Distribution, Temporal Stability and Appropriateness of Therapy of Patients with COPD in the UK in Relation to GOLD 2019. EClinicalMedicine. 2019;14:32-41. doi:10.1016/j.eclinm.2019.07.003

19. Han MK, Martinez CH, Au DH, et al. Meeting the challenge of COPD care delivery in the USA: a multiprovider perspective. Lancet Respir Med. 2016;4(6):473-526.

20. Ferguson GT, Rabe KF, Martinez FJ, et al. Triple therapy with budesonide/glycopyrrolate/formoterol fumarate with co-suspension delivery technology versus dual therapies in chronic obstructive pulmonary disease (KRONOS): a double-blind, parallel-group, multicentre, Phase 3 randomised controlled trial. Lancet Respir Med. 2018;6(10):747-758.

21. Lipson DA, Barnacle H, Birk R, et al. fulfil trial: once-daily triple therapy for patients with chronic obstructive pulmonary disease. Am J Respir Crit Care Med. 2017;196(4):438-446. doi:10.1164/ rccm.201703-0449OC

22. Lipson DA, Barnhart F, Brealey N, et al. Once-daily single-inhaler triple versus dual therapy in patients with COPD. $N$ Engl J Med. 2018;378(18):1671-1680. doi:10.1056/NEJMoa1713901

23. Papi A, Vestbo J, Fabbri L, et al. Extrafine inhaled triple therapy versus dual bronchodilator therapy in chronic obstructive pulmonary disease (TRIBUTE): a double-blind, parallel group, randomised controlled trial. Lancet. 2018;391(10125):1076-1084. doi:10.1016/ S0140-6736(18)30206-X

24. Rabe KF, Martinez FJ, Ferguson GT, et al. Triple Inhaled Therapy at Two Glucocorticoid Doses in Moderate-to-VerySevere COPD. N Engl J Med. 2020;383(1):35-48. doi:10.1056/ NEJMoa1916046

25. Singh D, Papi A, Corradi M, et al. Single inhaler triple therapy versus inhaled corticosteroid plus long-acting $\beta 2$-agonist therapy for chronic obstructive pulmonary disease (TRILOGY): a double-blind, parallel group, randomised controlled trial. Lancet. 2016;388 (10048):963-973. doi:10.1016/S0140-6736(16)31354-X

26. Vestbo J, Fabbri L, Papi A, et al. Inhaled corticosteroid containing combinations and mortality in COPD. Eur Respir J. 2018;52(6):6. doi:10.1183/13993003.01230-2018

27. Agusti A, Fabbri LM, Singh D, et al. Inhaled corticosteroids in COPD: friend or foe? Eur Respir J. 2018;52(6):6. doi:10.1183/ 13993003.01219-2018
28. Lipworth B, Kuo CR, Jabbal S. Current appraisal of single inhaler triple therapy in COPD. Int $J$ Chron Obstruct Pulmon Dis. 2018;13:3003-3009. doi:10.2147/COPD.S177333

29. Vanfleteren L, Fabbri LM, Papi A, Petruzzelli S, Celli B. Triple therapy (ICS/LABA/LAMA) in COPD: time for a reappraisal. Int J Chron Obstruct Pulmon Dis. 2018;13:3971-3981. doi:10.2147/COPD.S185975

30. Mammen MJ, Lloyd DR, Kumar S, et al. Triple therapy versus dual or monotherapy with long-acting bronchodilators for chronic obstructive pulmonary disease. a systematic review and meta-analysis. Ann Am Thorac Soc. 2020;17(10):1308-1318. doi:10.1513/AnnalsATS.202001$023 \mathrm{OC}$

31. Hartley BF, Barnes NC, Lettis S, Compton CH, Papi A, Jones P. Risk factors for exacerbations and pneumonia in patients with chronic obstructive pulmonary disease: a pooled analysis. Respir Res. 2020;21(1):5. doi:10.1186/s12931-019-1262-0

32. Han MK, Criner GJ, Dransfield MT, et al. The effect of inhaled corticosteroid withdrawal and baseline inhaled treatment on exacerbations in the impact study. a randomized, double-blind, multicenter clinical trial. Am J Respir Crit Care Med. 2020;202(9):1237-1243. doi:10.1164/rccm.201912-24780C

33. European Medicines Agency (EMA). Pharmacovigilance Risk Assessment Committee (PRAC), recommendation 2016. Inhaled corticosteroids (ICS) containing medicinal products indicated in the treatment of chronic obstructive pulmonary disease (COPD). 2016; Available from: https:/www.ema.europa.eu/medicines/human/refer rals/inhaled-corticosteroids-containing-medicinal-products-indicatedtreatment-chronic-obstructive. Accessed February 11, 2021.

34. European Medicines Agency (EMA). Committee for Medicinal Products for Human Use (CHMP), Assessment Report 2018. Trimbow International non-proprietary name: beclometasone dipropionate/formoterol fumarate dihydrate/glycopyrronium. Procedure No. EMEA/H/C/ 004257/II/0002. 2018; Available from: https://www.ema.europa.eu/en/ documents/variation-report/trimbow-h-c-4257-ii-0002-epar-assessmentreport-variation_en.pdf. Accessed February 11, 2021.

35. EU Clinical Trials Register. A multinational, multicentre, randomised, open-label, active-controlled, 26-week, 2-arm, parallel group study to evaluate the non-inferiority of fixed combination of beclometasone dipropionate plus formoterol fumarate plus glycopyrronium bromide administered via pMDI (CHF 5993) versus fixed combination of fluticasone furoate plus vilanterol administered via DPI (Relvar ${ }^{\circledR}$ ) plus tiotropium bromide $\left(\right.$ Spiriva ${ }^{\circledR}$ ) for the treatment of patients with chronic obstructive pulmonary disease. EudraCT number 2014-001487-35. 2018; Available from: https://www.clinicaltrialsregister.eu/ctr-search /trial/2014-001487-35/results. Accessed February 11, 2021.

36. Gershon AS, Guan J, Victor JC, Goldstein R, To T. Quantifying health services use for chronic obstructive pulmonary disease. Am $J$ Respir Crit Care Med. 2013;187(6):596-601. doi:10.1164/ rccm.201211-2044OC

37. Johannesdottir SA, Christiansen CF, Johansen MB, et al. Hospitalization with acute exacerbation of chronic obstructive pulmonary disease and associated health resource utilization: a population-based Danish cohort study. J Med Econ. 2013;16 (7):897-906. doi:10.3111/13696998.2013.800525

38. Soler-Cataluna JJ. Severe acute exacerbations and mortality in patients with chronic obstructive pulmonary disease. Thorax. 2005;60(11):925-931. doi:10.1136/thx.2005.040527

39. Soler-Cataluna JJ, Martinez-Garcia MÁ, Sanchez LS, Tordera MP, Sanchez PR. Severe exacerbations and BODE index: two independent risk factors for death in male COPD patients. Respir Med. 2009;103(5):692-699. doi:10.1016/j.rmed.2008.12.005

40. Rothnie KJ, Mullerova H, Smeeth L, Quint JK. Natural history of chronic obstructive pulmonary disease exacerbations in a general practice-based population with chronic obstructive pulmonary disease. Am J Respir Crit Care Med. 2018;198(4):464-471. doi:10.1164/ rccm.201710-2029OC 
41. Calverley PMA, Anderson JA, Celli B, et al. Salmeterol and fluticasone propionate and survival in chronic obstructive pulmonary disease. $N$ Engl J Med. 2017;196(4):775-789. doi:10.1056/ NEJMoa063070

42. Vestbo J, Anderson JA, Brook RD, et al. Fluticasone furoate and vilanterol and survival in chronic obstructive pulmonary disease with heightened cardiovascular risk (SUMMIT): a double-blind randomised controlled trial. Lancet. 2016;387(10030):1817-1826.

43. Lipson DA, Crim C, Criner GJ, et al. Reduction in all-cause mortality with fluticasone furoate/umeclidinium/vilanterol in patients with chronic obstructive pulmonary disease. Am J Respir Crit Care Med. 2020;201(12):1508-1516.

44. Randomised trial of cholesterol lowering in. 4444 patients with coronary heart disease: the Scandinavian Simvastatin Survival Study (4S). Lancet. 1994;344(8934):1383-1389.

45. UK Prospective Diabetes Study (UKPDS) Group. Effect of intensive blood-glucose control with metformin on complications in overweight patients with type 2 diabetes (UKPDS 34). UK Prospective Diabetes Study (UKPDS) Group. Lancet. 1998;352(9131):854-865.

46. Anthonisen NR, Skeans MA, Wise RA, et al. The effects of a smoking cessation intervention on 14.5-year mortality: a randomized clinical trial. Ann Intern Med. 2005;142(4):233-239.

47. Yusuf S, Sleight P, et al.; Heart Outcomes Prevention Evaluation Study I. Effects of an angiotensin-converting-enzyme inhibitor, ramipril, on cardiovascular events in high-risk patients. $N$ Engl $J$ Med. 2000;342(3):145-153.

48. Heart Protection Study Collaborative G. MRC/BHF Heart Protection Study of cholesterol lowering with simvastatin in 20,536 high-risk individuals: a randomised placebo-controlled trial. Lancet. 2002;360 (9326):7-22.

49. Williams NP, Coombs NA, Johnson MJ, et al. Seasonality, risk factors and burden of community-acquired pneumonia in COPD patients: a population database study using linked health care records. Int J Chron Obstruct Pulmon Dis. 2017;12:313-322.

50. Vestbo J, Papi A, Corradi M, et al. Single inhaler extrafine triple therapy versus long-acting muscarinic antagonist therapy for chronic obstructive pulmonary disease (TRINITY): a double-blind, parallel group, randomised controlled trial. Lancet. 2017;389 (10082):1919-1929.

51. Dransfield MT, Bourbeau J, Jones PW, et al. Once-daily inhaled fluticasone furoate and vilanterol versus vilanterol only for prevention of exacerbations of COPD: two replicate double-blind, parallel-group, randomised controlled trials. Lancet Respir Med. 2013;1(3):210-223.

52. Papi A, Dokic D, Tzimas W, et al. Fluticasone propionate/formoterol for COPD management: a randomized controlled trial. Int J Chron Obstruct Pulmon Dis. 2017;12:1961-1971.

53. Sharafkhaneh A, Southard JG, Goldman M, Uryniak T, Martin UJ. Effect of budesonide/formoterol pMDI on COPD exacerbations: a double-blind, randomized study. Respir Med. 2012;106(2):257-268.

54. Vogelmeier C, Paggiaro PL, Dorca J, et al. Efficacy and safety of aclidinium/formoterol versus salmeterol/fluticasone: a phase 3 COPD study. Eur Respir J. 2016;48(4):1030-1039.

55. Wedzicha JA, Banerji D, Chapman KR, et al. IndacaterolGlycopyrronium versus Salmeterol-Fluticasone for COPD. $N$ Engl $J$ Med. 2016;374(23):2222-2234.

56. Wedzicha JA, Calverley PM, Seemungal TA, et al. The prevention of chronic obstructive pulmonary disease exacerbations by salmeterol/ fluticasone propionate or tiotropium bromide. Am J Respir Crit Care Med. 2008;177(1):19-26.

57. Wedzicha JA, Singh D, Vestbo J, et al. Extrafine beclomethasone/ formoterol in severe COPD patients with history of exacerbations. Respir Med. 2014;108(8):1153-1162.

58. Williams NP, Ostridge K, Devaster JM, et al. Impact of radiologically stratified exacerbations: insights into pneumonia aetiology in COPD. Respir Res. 2018;19(1):143.
59. Hurst JR. Consolidation and Exacerbation of COPD. Med Sci. 2018;6:2.

60. Restrepo MI, Sibila O, Anzueto A. Pneumonia in Patients with Chronic Obstructive Pulmonary Disease. Tuberc Respir Dis. 2018;81(3):187-197.

61. Saleh A, Lopez-Campos JL, Hartl S. The effect of incidental consolidation on management and outcomes in COPD Exacerbations: data from the European COPD Audit. PLoS One. 2015;10(7): e0134004.

62. Dransfield M, Crim C, Criner G, et al. Risk of exacerbation and pneumonia with single inhaler triple therapy versus dual therapy in IMPACT. Eur Respir J. 2018;52(suppl62):PA1991.

63. Bafadhel M, Peterson S, De Blas MA, et al. Predictors of exacerbation risk and response to budesonide in patients with chronic obstructive pulmonary disease: a post-hoc analysis of three randomised trials. Lancet Respir Med. 2018;6(2):117-126.

64. Pascoe S, Barnes N, Brusselle G, et al. Blood eosinophils and treatment response with triple and dual combination therapy in chronic obstructive pulmonary disease: analysis of the IMPACT trial. Lancet Respir Med. 2019;7(9):745-756.

65. Pascoe S, Pavord I, Hinds D, Locantore N, Barnes N. The association between blood eosinophils and risk and treatment outcome in COPD is not dichotomised. Lancet Respir Med. 2018a;6(5):e18.

66. Bateman ED, Chapman KR, Singh D, et al. Aclidinium bromide and formoterol fumarate as a fixed-dose combination in COPD: pooled analysis of symptoms and exacerbations from two six-month, multicentre, randomised studies (ACLIFORM and AUGMENT). Respir Res. 2015;16:92.

67. Cazzola M, Molimard M. The scientific rationale for combining long-acting beta2-agonists and muscarinic antagonists in COPD. Pulm Pharmacol Ther. 2010;23(4):257-267.

68. Farne HA, Cates CJ. Long-acting beta2-agonist in addition to tiotropium versus either tiotropium or long-acting beta2-agonist alone for chronic obstructive pulmonary disease. Cochrane Database Syst Rev. 2015;10:CD008989.

69. Mahler DA, Decramer M, D’Urzo A, et al. Dual bronchodilation with QVA149 reduces patient-reported dyspnoea in COPD: the BLAZE study. Eur Respir J. 2014;43(6):1599-1609.

70. Singh D, Ferguson GT, Bolitschek J, et al. Tiotropium + olodaterol shows clinically meaningful improvements in quality of life. Respir Med. 2015;109(10):1312-1319.

71. van der Molen T, Cazzola M. Beyond lung function in COPD management: effectiveness of LABA/LAMA combination therapy on patient-centred outcomes. Prim Care Respir J. 2012;21 (1):101-108.

72. Wilkie M, Finch S, Schembri S. Inhaled Corticosteroids for chronic obstructive pulmonary disease-the shifting treatment paradigm. COPD. 2015;12(5):582-590.

73. Bjermer L, Kerwin E, Maltais F, et al. Comparative efficacy and safety of umeclidinium/ vilanterol, umeclidinium and salmeterol in symptomatic maintenance-naïve and maintenance-treated chronic obstructive pulmonary disease: a prospective analysis of the EMAX trial. Am J Respir Crit Care Med. 2019;199:A3317.

74. Maltais F, Bjermer L, Kerwin EM, et al. Efficacy of umeclidinium/ vilanterol versus umeclidinium and salmeterol monotherapies in symptomatic patients with COPD not receiving inhaled corticosteroids: the EMAX randomised trial. Respir Res. 2019;20(1):238.

75. Decramer M, Anzueto A, Kerwin E, et al. Efficacy and safety of umeclidinium plus vilanterol versus tiotropium, vilanterol, or umeclidinium monotherapies over 24 weeks in patients with chronic obstructive pulmonary disease: results from two multicentre, blinded, randomised controlled trials. Lancet Respir Med. 2014;2 (6):472-486.

76. Oba Y, Sarva ST, Dias S. Efficacy and safety of long-acting beta-agonist/long-acting muscarinic antagonist combinations in COPD: a network meta-analysis. Thorax. 2016;71(1):15-25. 
77. Calzetta L, Rogliani P, Matera MG, Cazzola M, Systematic Review A. With meta-analysis of dual bronchodilation with LAMA/LABA for the Treatment of Stable COPD. Chest. 2016;149 (5):1181-1196.

78. Maleki-Yazdi MR, Singh D, Anzueto A, Tombs L, Fahy WA, Assessing Short-term NI. Deterioration in maintenance-naive patients with COPD receiving umeclidinium/vilanterol and tiotropium: a pooled analysis of three randomized trials. Adv Ther. 2017;33 (12):2188-2199.

79. Singh D, Gaga M, Schmidt O, et al. Effects of tiotropium + olodaterol versus tiotropium or placebo by COPD disease severity and previous treatment history in the OTEMTO(R) studies. Respir Res 2016;17(1):73.

80. Gaduzo S, McGovern V, Roberts J, Scullion JE, Singh D. When to use single-inhaler triple therapy in COPD: a practical approach for primary care health care professionals. Int J Chron Obstruct Pulmon Dis. 2019;14:391-401.

81. Perera PN, Armstrong EP, Sherrill DL, Skrepnek GH. Acute exacerbations of COPD in the United States: inpatient burden and predictors of costs and mortality. COPD. 2012;9(2):131-141.

82. Yu AP, Guerin A. Ponce de Leon D, et al. Therapy persistence and adherence in patients with chronic obstructive pulmonary disease multiple versus single long-acting maintenance inhalers. J Med Econ. 2011;14(4):486-496.

83. Zhang S, King D, Rosen VM, Ismaila AS. Impact of single combination inhaler versus multiple inhalers to deliver the same medications for patients with asthma or COPD: a systematic literature review. Int J Chron Obstruct Pulmon Dis. 2020;15:417-438.

84. Makela MJ, Backer V, Hedegaard M, Larsson K. Adherence to inhaled therapies, health outcomes and costs in patients with asthma and COPD. Respir Med. 2013;107(10):1481-1490.
85. Lopez-Campos JL, Quintana Gallego E, Carrasco Hernandez L. Status of and strategies for improving adherence to COPD treatment. Int J Chron Obstruct Pulmon Dis. 2019;14:1503-1515.

86. Halpin DMG, Worsley S, Ismaila AS, et al. INTREPID: clinical effectiveness of once-daily single-inhaler fluticasone furoate/umeclidinium/vilanterol versus multiple-inhaler triple therapy in usual clinical practice. Am J Respir Crit Care Med. 2020;201:A4313.

87. GlaxoSmithKline. A comparison study between the fixed dose triple combination of fluticasone furoate/umeclidinium/vilanterol trifenatate (FF/UMEC/VI) with budesonide/formoterol in subjects with chronic obstructive pulmonary disease (COPD) - Study 116853 (NCT02345161). Available from: https://www.gsk-studyregister. com/en/trial-details/?id=116853. Accessed February 11, 2021.

88. Rabe KF, Martinez FJ, Singh D, et al. Improvements in lung function with budesonide/glycopyrrolate/formoterol fumarate metered dose inhaler (BGF MDI) versus dual therapies in patients with COPD: a sub-study of the ETHOS trial. American Thoracic Society - 116th International Conference; 2020.

89. GlaxoSmithKline. A study comparing the efficacy, safety and tolerability of fixed dose combination (FDC) of FF/UMEC/VI with the FDC of FF/VI and UMEC/VI; administered once-daily via a dry powder inhaler (DPI) in subjects with chronic obstructive pulmonary disease (COPD) - Study 116855 (NCT02164513).Available from: https://www.gsk-studyregister.com/en/trial-details/?id=116855. Accessed February 11, 2021.

90. Rabe KF, Martinez FJ, Ferguson GT, et al. A Phase III study of triple therapy with budesonide/glycopyrrolate/formoterol fumarate metered dose inhaler 320/18/9.6mug and 160/18/9.6mug using co-suspension delivery technology in moderate-to-very severe COPD: the ETHOS study protocol. Respir Med. 2019;158:59-66.

\section{Publish your work in this journal}

The International Journal of COPD is an international, peer-reviewed journal of therapeutics and pharmacology focusing on concise rapid reporting of clinical studies and reviews in COPD. Special focus is given to the pathophysiological processes underlying the disease, intervention programs, patient focused education, and self management protocols. This journal is indexed on PubMed Central, MedLine and CAS. The manuscript management system is completely online and includes a very quick and fair peer-review system, which is all easy to use. Visit http://www.dovepress.com/testimonials.php to read real quotes from published authors. 